\title{
Analysis and Implementation Path of Precision Poverty Alleviation Policy in China
}

\begin{abstract}
Yang Baoguo
Xijing University, Shaanxi, China

Keywords: Precision Poverty Alleviation; Implementation Path; shortcomings

Abstract: Since the reform and opening-up, China has been focusing on poverty alleviation. The number of poor people in China has declined year by year. Precision Poverty Alleviation has been implemented in 2013. By the end of 2017, great achievements have been made in poverty alleviation. However, there are still some shortcomings in the development of precise poverty alleviation. This paper points out the precise poverty alleviation policy in China. Finally, three suggestions are given to promote the poverty alleviation in China to achieve faster and better results.
\end{abstract}

\section{Introduction}

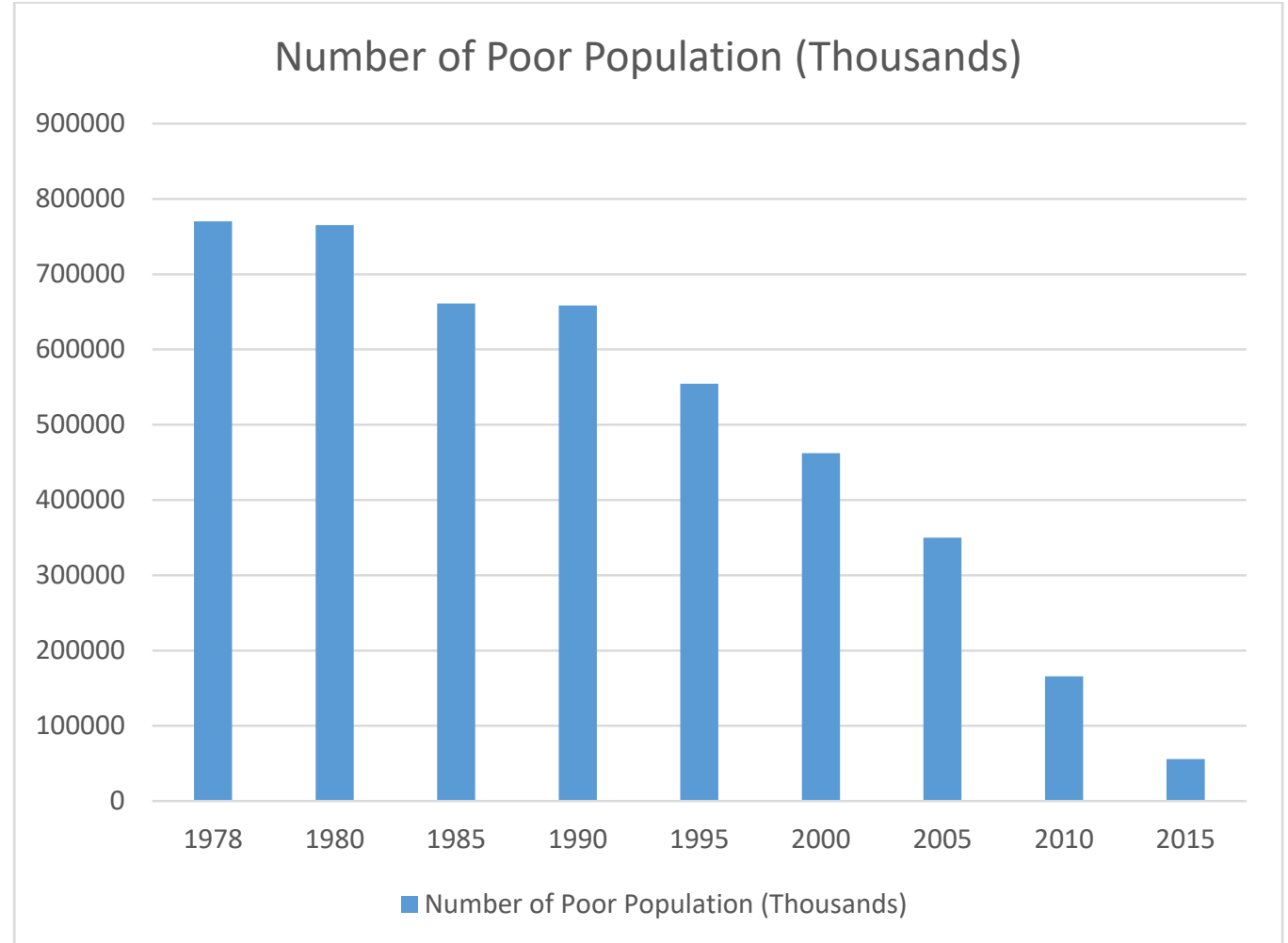

Figure 1: The number of poor people in China from 1978 to 2015 
Since the reform and opening up, China's economy has developed rapidly, and the number of poor people in China has declined significantly year by year. Figure 1 shows the change chart of the number of poor people in China from 1978 to 2015.

On February 1, 2018, the National Statistical Bureau issued "The Poverty Reduction in Rural Areas and the Income Growth of Rural Residents in Poverty-stricken Areas Accelerated in 2017". According to the data, according to a sample survey of 160,000 households in 31 provinces in China, by the end of 2017, according to the national rural poverty standard (the poverty line in 2016 is about 3,000 yuan per capita net income), the poverty-stricken population in rural areas was estimated to be 30.46 million, a decrease of 12.89 million compared with the end of last year.

It can be seen that the number of people living in poverty has decreased by 12.89 million compared with the previous year, and the government has made significant progress in poverty alleviation. However, the central and western parts of the disaster-stricken areas of the rural poor account for about $90 \%$ of the country's rural poor, and the work of poverty alleviation in the central and western regions still has a long way to go. Therefore, the development of precise poverty alleviation can better alleviate the economic lag in poor areas, so the innovative ways of precise poverty alleviation have a very important position in the current poverty alleviation policy research.

\section{The Process of Proposing Precision Poverty Alleviation Policy in China}

Rural poverty in China is a serious obstacle to social development under the dual structure of urban and rural areas. It is also the main limiting factor that affects the common sustainable development of urban and rural areas. Because of the different economic types and social development stages in different regions, the policies of poverty control are also different. Our country has gone through many years. Practice and exploration have gradually formed a socialist economic poverty alleviation system with Chinese characteristics. China's economic poverty alleviation policy has gone through the stage of development of reducing poverty through the reform of the rural system, a planned large-scale poverty alleviation policy with poverty-stricken areas as its main object, and an opening aimed at solving the problem of people's food and clothing. There are five stages of poverty alleviation policy in the development stage, the poverty alleviation plan to improve the basic living conditions of poor areas and consolidate the problem of food and clothing, and the precise poverty alleviation plan to improve the living standard of our people. China's poverty alleviation plan has been gradually upgraded from solving the problem of food and clothing to an accurate poverty alleviation plan to improve the living standard of the people. It reflects that the goal of our poverty alleviation policy is clearer and the measures are more specific. It adapts to the characteristics of the development stage of our country's economy and is more in line with the actual development of rural poverty in our country.

With the deepening of China's poverty alleviation policy and the constant change of poverty in rural areas, China's poverty alleviation policy is facing new challenges: due to the complexity and diversity of China's poverty problem, the relative poverty problem is aggravating, and the disability problem is still a prominent problem; Poverty-stricken areas in China have poor geographical conditions and strong population mobility. Most of the poor areas are left-behind elderly, with relatively low labor capacity and cultural level. In many places, the educational environment and resources are quite backward, as shown in Figure 2. Therefore, the main body of poverty in China is characterized by fragmentation and vulnerability. The development of poverty-stricken areas is one of the important ways for the government to promote the development of poverty-stricken areas, and its economic responsibility is even greater. With the proposal of realizing the goal of a well-off society in an all-round way by 2020, optimizing poverty alleviation funds and resources, innovating Poverty Alleviation Policies and achieving precise poverty alleviation have become the most 
important problem for the government to solve.

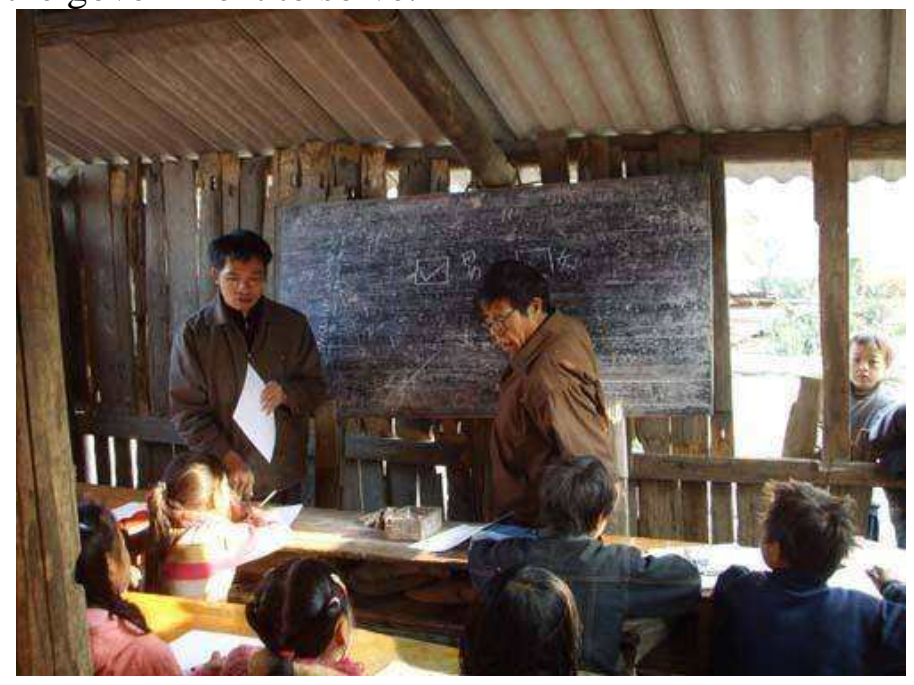

Figure 2: Poor Teaching Environment in Poverty-stricken Areas

\section{Problems in China's Precision Poverty Alleviation Policy}

Since the implementation of precise poverty alleviation in China in 2013, all parts of the country have been actively exploring effective precise poverty alleviation models, and have formulated many policies, which play an important supporting role in promoting the development of precise poverty alleviation and achieving good results. For example, in order to carry out precise poverty alleviation, insurance policies have been established in many places. For example, some places continue to innovate precise poverty alleviation model and carry out industrialization precise poverty alleviation, which should be said to be innovative, but also play a positive role! But in-depth analysis of precise Poverty Alleviation Policies in some parts of China,Although it can be carried out in accordance with the requirements of the state in general, there are also some problems and shortcomings in the process of implementation. Lack of efficiency mechanism, lack of resource integration and lack of model innovation in poverty alleviation work lead to the lack of support and guidance for precise poverty alleviation policies. Especially if it is not closely integrated with rural economic development, it needs to be seriously solved.

\section{Solutions to Precision Poverty Alleviation}

\subsection{Improving the Dynamic Management and Assessment Mechanism of Precision Poverty Alleviation Policy}

In order to do a good job of precise poverty alleviation, we should establish a sound dynamic management and assessment mechanism of precise poverty alleviation policy, constantly innovate the micro-credit poverty alleviation policy and implementation mode, establish a perfect credit mechanism for farmers, so that real farmers do not need guarantees, interest-free loan system! We should further improve and innovate poverty. Regional social security and social assistance mechanisms, diversified insurance mechanisms, irregular field visits by government staff and relevant staff, dynamic supervision, continuous improvement of disaster relief in rural areas such as major injuries and diseases, purchase of new cooperative medical care and old-age insurance for poor families, and so on. We should do a good job of dynamic supervision so as to achieve real and precise poverty alleviation. 


\subsection{Improving the information of poverty-stricken households'archiving and establishing a multi-faceted poverty identification system}

In order to understand the situation of poverty-stricken peasant households and enhance the identification of poverty-stricken peasant households in China from various aspects, we should promote the links between the information of building files and establishing cards and real estate on the basis of existing poverty identification and archiving, improve the basic information of poverty-stricken peasant households, establish and improve the multi-scale and multi-dimensional identification methods of poverty-stricken peasant household Income ability, labor ability and consumption ability are organically combined with the identification criteria of poor peasant households. Different peasant households are analyzed in different ways. Emphasis is laid on the analysis of different types of poor peasant households. Information bases of different types of poor peasant households are constructed, comprehensive poverty identification methods suitable for China's national conditions are constructed, and diversified precise poverty reduction indicators are Departments and assessment methods provide support for precise poverty alleviation in China.

\subsection{Establishment of a precise poverty alleviation responsibility table and a poverty alleviation schedule}

All levels of poverty alleviation units and relevant staff in China should further clarify each task of the Poverty Alleviation Office and various departments, and form a detailed responsibility task list so as to avoid missing tasks or duplication of tasks. In addition, the sequence of tasks and responsibilities should be clearly defined, and the focus of poverty alleviation and poverty alleviation of social participation should be clarified. Guiding and avoiding the inefficient use of poverty alleviation resources, in order to improve the efficient use of poverty alleviation resources, we should also accelerate the diversified cooperation ability of special poverty alleviation, industry poverty alleviation and social poverty alleviation, and clarify the responsibilities and progress of various poverty alleviation organizations.

\section{Conclusions}

To sum up, after years of development, our national economic strength has been greatly enhanced, and the precise poverty alleviation in China has made great progress. More and more people are living a well-off life, but there are still some shortcomings in the specific cause of poverty alleviation. We should pay attention to these shortcomings and strive to improve the policy dynamics of precise poverty alleviation. The management and assessment mechanism, improvement of poor households' archiving information, establishment of a well poverty identification system, formulation of a precise poverty alleviation responsibility table and poverty alleviation schedule should all be taken seriously. Only in this can China's poverty alleviation reach to a higher level.

\section{References}

[1] Zhang Zhiyong.Research on Precision Poverty Alleviation Policy and Its Innovative Path in China [J].Small and Medium-sized Enterprises Management and Science and Technology (Preliminary Journal), 2018(07):103-104.

[2] Li Hao.Implementing Dilemma and Innovative Path of Precision Poverty Alleviation Policy_Analysis of positive and negative cases based on precise poverty alleviation[J].Southern China,2018(04):11-14.

[3] Zheng Rui.Research on Precision Poverty Alleviation Policy and Its Innovative Path [J].knowledge economy, 2018(04):12-13.

[4] Xu Lixin.Research on Precision Poverty Alleviation Policy and Its Innovative Path in China [J].China high tech 
Zone, 2018(03):10.

[5] Wang Jieyong,Chen Yufu,Yan Maochao.Research on Precision Poverty Alleviation Policy and Its Innovative Path in China[J].Bulletin of Chinese Academy of Sciences,2016,31(03):289-295. 